\title{
Chemotherapy-induced peripheral neurotoxicity and complementary and alternative medicines: progress and perspective
}

OPEN ACCESS

Edited by:

Xue-Jun Sun,

Second Military Medical University,

China

Reviewed by:

Liren Qian,

Navy General Hospital, China

Xiao Yu Tian,

Houston Methodist Research

Institute, USA

*Correspondence:

Peng Cao

pcao79@yahoo.com

tThese authors have contributed equally to this work.

Specialty section: This article was submitted to

Ethnopharmacology,

a section of the journal

Frontiers in Pharmacology

Received: 14 July 2015 Accepted: 01 October 2015 Published: 23 October 2015

Citation:

Cheng XL, Liu HQ, Wang Q, Huo JG,

Wang XN and Cao P (2015)

Chemotherapy-induced peripheral

neurotoxicity and complementary and alternative medicines: progress and perspective.

Front. Pharmacol. 6:234. doi: 10.3389/fphar.2015.00234
Xiao L. Cheng ${ }^{1,2+}$, Hong Q. Liu' ${ }^{1 \dagger}$, Qi Wang ${ }^{3}$, Jie G. Huo', Xiao N. Wang' and Peng Cao ${ }^{1,2 *}$

${ }^{1}$ Affiliated Hospital of Integrated Traditional Chinese and Western Medicine, Nanjing University of Chinese Medicine, Nanjing, China, ${ }^{2}$ Laboratory of Cellular and Molecular Biology, Jiangsu Province Academy of Traditional Chinese Medicine, Nanjing, China, ${ }^{3}$ Jiangsu Shenlong Pharmaceutical Co., Ltd., Yancheng, China

Chemotherapy-induced peripheral neurotoxicity (CIPN) is a severe and dose-limiting side effect of antineoplastic drugs. It can cause sensory, motor and autonomic system dysfunction, and ultimately force patients to discontinue chemotherapy. Until now, little is understood about CIPN and no consistent caring standard is available. Since CIPN is a multifactorial disease, the clinical efficacy of single pharmacological drugs is disappointing, prompting patients to seek alternative treatment options. Complementary and alternative medicines (CAMs), especially herbal medicines, are well known for their multifaceted implications and widely used in human health care. Up to date, several phytochemicals, plant extractions, and herbal formulas have been evaluated for their potential therapeutic benefit of preventing the onset and progression of CIPN in experimental models. Clinical acupuncture has also been shown to improve CIPN symptoms. In this review, we will give an outline of our current knowledge regrading the advanced research of CIPN, the role of CAMs in alleviating CIPN and possible lacunae in research that needs to be addressed.

Keywords: chemotherapy-induced peripheral neurotoxicity, complementary and alternative medicine, herbal medicine, acupuncture, Pathogenesis

\section{INTRODUCTION}

Chemotherapy-induced peripheral neurotoxicity (CIPN) is a severe adverse effect of antineoplastic drugs like taxanes, platinum drugs, vinca alkaloids as well as proteasome inhibitors bortezomib (Miltenburg and Boogerd, 2014). These regimens affect sensory nerves and lead to slow action potential, considerable pain, functional loss, and ultimately chemotherapy withdrawal (Jaggi and Singh, 2012). Generally, CIPN is characterized by pain, tingling, numbness, and impaired sensory function in hands and feet (Miltenburg and Boogerd, 2014). In some cases, motor nerves and autonomic nervous system may also be involved, depending on the antineoplastic agents used (Argyriou et al., 2014). Over the past decades, many valuable strategies such as OPTIMOX (stop and go) have been proposed for CIPN prevention (Hershman et al., 2014). However, dose reduction or cessation can increase cancer-related morbidity and mortality. Hence, an alternative or novel approach is required to treat or prevent CIPN.

Complementary and alternative medicine (CAM), differing from medical mainstream, is historic and widely utilized to treat health conditions throughout the world. Based on recent 
literatures, several CAM methods exhibiting promising effects on CIPN or a putative influence on mechanisms of CIPN have been identified. Due to its multilevel, multitarget, and coordinated intervention effects, CAM seems to be a promising and viable choice for CIPN prevention. In this review, we will focus on the new insights on the molecular mechanisms of CIPN, and highlight the importance of CAM in alleviating CIPN. Additionally, the strategies for the future research are also proposed in this paper.

\section{PATHOGENESIS OF CIPN}

Although CIPN have been well explored with the advent of rodent models over the past decade, its exact pathogenesis still remains unclear (Han and Smith, 2013; Carozzi et al., 2015). Recent studies showed that multiple mechanisms including structural changes in peripheral nerves, DNA damage, mitochondria changes, increased oxidative stress, alterations in ion channels, and neuroinflammation activation contributed to the peripheral neurotoxicity development (Figure 1, Miltenburg and Boogerd, 2014; Carozzi et al., 2015). In this paper, the main mechanisms involving in CIPN development were reviewed.

\section{Structural Changes in Peripheral Nerves}

Peripheral nervous system is susceptible to the neurotoxins accumulation due to the absence of vascular barrier and lymph drainage. After exposured to chemotherapeutic agents, the longest axons and myelinated fibers are damaged, accompanying reduced sensory nerve conduction velocity and intraepidermal nerve fiber (IENF) loss (Bennett et al., 2011; Boyette-Davis et al., 2011; Zheng et al., 2012). Peripheral nerve degeneration or progressive IENF loss are considered as the key neuropathologies of CIPN. Usually, the structural changes in peripheral nerves may lead to the development of clinical symptoms in the feet and hands, as described as a "stocking and glove" distribution (Han and Smith, 2013). The decrease in IENF density is correlated with the severity of painful neuropathy and hyperexcitability. In CIPN, A $\delta$ (cool specific) and C fibers (warm specific) losses are also observed from nociceptors, resulting in cold-allodynia (Polomano et al., 2001; Flatters and Bennett, 2004). In general, the structural damage extent of peripheral nerves depends on the type of antineoplastic drugs and the dosing regimen, as needs to be further investigated systematically and confirmed in the rodent models.

\section{Mitochondrial Dysfunction and Oxidative Stress}

Accumulating evidences suggest mitochondrion is a key target of CIPN (Poratz et al., 2011; Zheng et al., 2012). After exposure to toxic concentrations of antineoplastic drugs, a reduction in functional mitochondria and a loss of mitochondrial membrane potential and ultra-structural changes were observed in cultured DRG sensory neurons, suggesting subcellular vacuolar degeneration (Melli et al., 2008). In vivo studies,

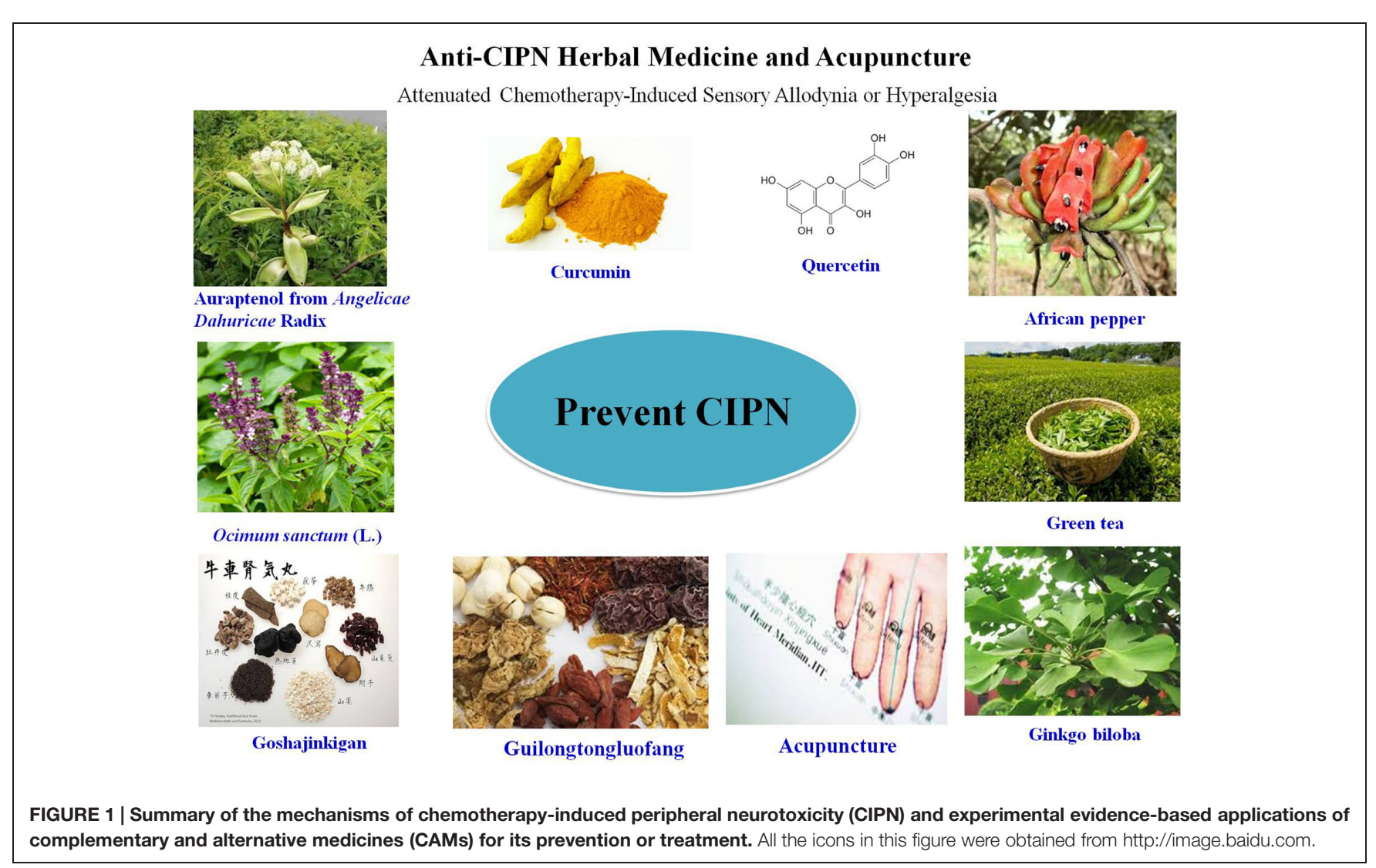


histological observations on peripheral nerve of CIPN animals show swollen and vacuolated mitochondria (Melli et al., 2008). The incidence of vacuolated mitochondria in sensory nerve fibers of paclitaxel- or oxaliplatin-treated rats are greatly higher than that in vehicle control group (37.3 and 152\%, respectively; Xiao and Bennett, 2012). In patients with CIPN induced by vincristine and bortezomib, the expression of genes controlling the mitochondrial function is significantly changed (Broyl et al., 2010). Anticancer drugs induce mitochondria damage mainly through impairments of ATPase-dependent $\mathrm{Na} / \mathrm{K}$ pumps and calcium homeostasis alterations. Reducing mitochondrial impairment or suppressing mitochondrial electron transport chain and ATP synthesis was shown to attenuate neurotoxicity symptoms, supporting the important role of mitochondrion in CIPN development (Melli et al., 2008). Accumulation of dysfunctional mitochondria would lead to an increase in oxidative stress, which is also involved in peripheral nerve damage (Sandireddy et al., 2014). In CIPN animals, oxidative stress markers such as oxidative lipid, protein, and DNA damage are dramatically increased in sciatic nerve and lumbar spinal cord (Florea and Büsselberg, 2011; Wang et al., 2011; Di Cesare et al., 2012). Compounds with antioxidant property are demonstrated to relieve the CIPN symptoms (Fidanboylu et al., 2011; Kim et al., 2011). Recently, Nrf2 and NF$\kappa \mathrm{B}$ have been revealed to be co-ordinated for maintenance of redox homeostasis in healthy cells (GaneshYerra et al., 2013). A decline in Nrf2 activity and a persistent increase in $\mathrm{NF}-\kappa \mathrm{B}$ activity can lead to neuroinflammation and increase oxidative stress, which further result in the development of peripheral neuropathy (GaneshYerra et al., 2013). Hence, agents that can regulate the crosstalk between $\mathrm{Nrf} 2$ and $\mathrm{NF}-\kappa \mathrm{B}$ might be promising to prevent or treat CIPN (Negi et al., 2011).

\section{Ion Channels}

Ion channels including voltage gated $\mathrm{Na}^{+}$and TRP channels have significant roles in CIPN development (Goswami, 2012; Argyriou et al., 2013). Changes in $\mathrm{Na}^{+}$channel induce ectopic activity in primary afferent neurons and result in paraesthesia and fasciculations (Webster et al., 2005). In a previous study, oxaliplatin was found to increase $\mathrm{Na}^{+}$current in DRG neurons. However, in another work oxaliplatin slowed inactivation kinetics of $\mathrm{Na}^{+}$channel, shifted the voltage dependence of gating, and reduced overall $\mathrm{Na}^{+}$current (Sittl et al., 2012). Paclitaxelinduced peripheral neuropathy is also associated with $\mathrm{Na}^{+}$ channels (Zhang et al., 2014). Tetrodotoxin, a $\mathrm{Na}^{+}$channel blocker, was able to ameliorate paclitaxel-induced pain (Nieto et al., 2008). Besides $\mathrm{Na}^{+}$channels, transient receptor potential channels such as TRPV1, TRPA1, and TRPM8 play a pivotal role as sensors for cold, mechanical (TRPA1 channels) and heat (TRPV1 channels) stimuli in CIPN models (Goswami, 2012; Hara et al., 2013; Sałat et al., 2013; Quartu et al., 2014). Cisplatin or oxaliplatin can increase expression of TRPA1, TRPM8, and TRPV1 mRNA in DRG neurons. TRPV1 is essential for the generation of thermal hyperalgesia caused by cisplatin (Gauchan et al., 2009a; Anand et al., 2010). Compared to wild-type mice, only mechanical allodynia without heat-evoked pain responses is observed in cisplatin-treated TRPV1-null mice (Ta et al., 2010). Oxaliplatin induces neuropathy partly through regulating TRPA1 and TRPM8 (Gauchan et al., 2009b). Administration of ADM-09, a TRPA1 blocker, is able to effectively abolish oxaliplatin-induced neurotoxicity in mice (Nativi et al., 2013). Besides TRPV1, TRPA1, and TRPM8, TRPV4 may be involved in chemotherapy-evoked peripheral neuropathy. In vincristine- or paclitaxel-treated mice lacking TRPV4, the occurrence of mechanical hyperalgesia was significantly reduced (Alessandri-Haber et al., 2008). Moreover, after spinal intrathecal administration of antisense oligodeoxynucleotides to TRPV4, the reduction of mechanical hyperalgesia was also observed. To date, studies of TRP channels remains limited and should be extended for seeking novel therapeutic strategies to management CIPN.

\section{Neuroinflammation}

Chemotherapy-induced peripheral neurotoxicity development is accompanied by a neuroinflammatory response. Once chemotherapy-induced injury occurs, numbers of inflammatory cells accumulate around damaged nerves, in response to the activation of Schwann cells and resident macrophages, and produce multiple cytokines and chemokines, such as TNF$\alpha$, IL-1 $\beta$, IL-6, IL-8, CCL2, and CXC family. These secreted inflammatory mediators can up-regulate the expression levels of ion channels like $\mathrm{Na}^{+}$and $\mathrm{Ca}^{2+}$, or directly activate nociceptors implicated in mechanical and thermal hyperalgesia, and cause peripheral sensitization (Schafers and Sorkin, 2008; Mangiacavalli et al., 2010; Wagner et al., 2011). Studies conducted by Ledeboer and his collaborators demonstrated an increase in pro-inflammatory cytokine gene expressions in paclitaxel-treated lumbar DRG (Ledeboer et al., 2007). Inhibition of inflammatory cytokines has been considered as a useful method for CIPN prevention (Wolf et al., 2006). In an animal model of paclitaxelinduced neuropathy, the mechanical allodynia response could be significantly reversed after IL-10 gene therapy through reducing the production of IL- $1 \beta$ and TNF- $\alpha$ in the DRG (Ledeboer et al., 2007). Toll-like receptors TLR2 and TLR4 in periphery may be involved in mechanical allodynia associated with anticancer drugs. Once stimulated with neurotoxic compounds, TLR2 and TLR4 were activated and then initiated inflammation and caused the elevation of proinflammatory cytokines (Akira and Takeda, 2004). Intrathecally delivered TLR4 receptor antagonists reversed the established mechanical allodynia evoked by paclitaxel (Hutchinson et al., 2008).

\section{Drug Transporters}

A recent study suggested that the neurotoxicity of platinum drugs was correlated with several classes of drug transporters (Ceresa and Cavaletti, 2011). Copper transporters (CTR1) and organic cation transporters (OCT2) have been recognized to be responsible passage for platinum drugs entering into DRG neurons (Ciarimboli et al., 2010; Liu et al., 2013). CTR1 and OCT2 expression was confirmed in the DRG neurons (Cavaletti et al., 2014). OCT2 overexpress can largely improve the uptake of oxaliplatin by 16- to 35-fold (Sprowl et al., 2013). In OCT2-knockout mice, oxaliplatin-induced cold 
hypersensitivity or mechanical allodynia were totally reversed, suggesting that oxaliplatin-induced peripheral neurotoxicity is dependently mediated by drug transporters, expecially OCT2. So far, knowledge about distribution and activity of platinum drugrelated transporters are still very limited, the co-expressions of these different drug transporters and their interplay should be carefully assessed.

\section{TREATMENT OPTIONS FOR CIPN AND LIMITATIONS}

So far a variety of pharmacological strategies have been tested to improve the neurological symptoms of CIPN. These promising drugs include PARP inhibitors, $\mathrm{Ca} / \mathrm{Mg}$, vitamin $\mathrm{E}$, amifostine, glutathione, glutamine, $\mathrm{N}$-acetylcysteine, acetyl-Lcarnitine, recombinant human leukemia inhibitory factor, and venlafaxine (Flatters et al., 2006; Cavaletti, 2011; Gobran, 2013; Ta et al., 2013). Although these medications have been proven to be effective in preventing CIPN, their therapeutic potential is limited due to contradictive conclusions and unexpected side effects (Wolf et al., 2008; Ceresa and Cavaletti, 2011). For example, $\mathrm{Ca} / \mathrm{Mg}$ decreased neuropathy by about $50 \%$ compared with a historical control group (Gobran, 2013). However, $\mathrm{Ca} / \mathrm{Mg}$ can interfere with the response to oxaliplatin-based chemotherapy, and is shown to be ineffective in a large phase III clinical trial (Gamelin et al., 2008; Loprinzi et al., 2014). Glutathione is useful for preventing CIPN in patients undergoing cisplatinbased chemotherapy (Leal et al., 2014). But glutathione may also diminish the antitumour activity of cisplatin through increasing the elimination of cisplatin from kidney (Wolf et al., 2008). To date, no agent has available evidence sufficient to recommend its clinical use for CIPN treatment.

\section{COMPLEMENTARY AND ALTERNATIVE MEDICINES FOR CIPN TREATMENT}

The lack of effectively curative strategies for CIPN promotes the urgent need to seek help from CAM. As a key complement for conventional medical therapy, CAM has been paid attention by the western country because of its less invasive, safe, effective, economical, and convenient therapeuticals benefits. CAM emphasizes on both disease prevention and treatment and has become an important method in treating chronic disease. Most recently, several CAM methods including traditional herbal medicines and acupuncture have been described to be beneficial on CIPN. In present review, clinical and experimental evidence supporting CAMs application for CIPN treatment have be summarized with a special focus on herbal medicines (Figure 1 and Table 1).

\section{Herbal Medicines}

\section{Curcumin}

Curcumin is the major active ingredient of turmeric and ginger, with strong antioxidant and anti-inflammatory activities. Curcumin has been shown to be a neuroprotective agent against neurological disorders, including diabetic neuropathy and alcoholic neuropathy (Ataie et al., 2010; Attia et al., 2012; Kandhare et al., 2012). In CIPN rat model, curcumin reduced plasma neurotensin and platinum uptake in sciatic nerve, and profoundly improved histopathological damages induced by oxaliplatin and cisplatin (Al Moundhri et al., 2013). In PC12 cells, curcumin could largely reversed the cisplatin-induced reduced neurite outgrowth of cells, without compromising anticancer activity (Mendonça et al., 2013). Curcumin ameliorated altered non-enzymatic and enzymatic antioxidants and complex enzymes of mitochondria, thus holding promise as agent that can potentially reduce platinum -induced peripheral neurotoxicity (Waseem and Parvez, 2015).

\section{Quercetin}

Quercetin is a flavonoid widely distributed in many plants and fruits including Bupleurum chinense DC., Morus alba L., Crataegus pinnatifida Bunge, red grapes, and citrus fruit, and has been reported to have powerful antioxidant, antinociceptive as well as anti-inflammatory properties. With several animal models, this compound showed remarkable antinociceptive and neuroprotective effects in alcohol and diabetic induced neuropathies (Wang et al., 2011; Raygude et al., 2012) threshold, prevented the shrinkage of neurons and inhibited light edema formation (Azevedo et al., 2013). Additionally, marker of neuroplasticity c-Fos was lower in quercetin pretreatment groups $(25,50$, and $100 \mathrm{mg} / \mathrm{kg})$ than that of oxaliplatin-treated rats. The action mechanism of quercetin is associated with its attenuation of mitochondrial dysfunction induced by oxaliplatin (Waseem and Parvez, 2015).

\section{Ginkgo biloba Extract}

Ginkgo biloba extract (GBE), the leaf extract of Ginkgo biloba $\mathrm{L}$., is a popular herbal product used for a variety of ischemic and neurological disorders. Growing studies have reported the antioxidant, anticancer, angiectatic, and neuroprotective potentials of GBE. The evidence for the protective role of GBE in ameliorating CIPN is also available in several in vivo studies (Oztürk et al., 2004; Park et al., 2012). In mice with peripheral neuropathy induced by cisplatin, oral administration of GBE $(100 \mathrm{mg} / \mathrm{kg} / \mathrm{d})$ for 4.5 weeks was demonstrated to promote axonal growth from DRG, and prevent the reduction in sensory nerve conduction velocity. Furthermore, reductions of length of outgrowing axons, and somatic and nuclear sizes of neurons were also reversed (Oztürk et al., 2004). In a rat model of vincristineinduced peripheral neuropathy, GBE significantly increased the paw-withdrawal threshold to mechanical stimulation and reduced withdrawal latency to cold stimuli (Park et al., 2012). The antihyperalgesic effect of GBE may be associated with its antioxidative actions, suppression of NF- $\mathrm{KB}, \mathrm{NO}$, and TNF- $\alpha$ production, inhibition of myelinated axons degradation and improvement of axonal transport.

\section{Green Tea}

Green tea is a popular beverage with attractive flavor, aroma, and health effect. The major bioactive compounds presented in green tea are catechins. Numerous published studies 
TABLE 1 | Summary of the proved effects of herbal medicines in chemotherapy-induced peripheral neurotoxicity (CIPN) model and neuropathy symptoms.

\begin{tabular}{|c|c|c|c|c|}
\hline Herbal medicines & Dose & Animal model & Mode of action & Reference \\
\hline \multirow[t]{2}{*}{ Ginkgo biloba } & $100 \mathrm{mg} / \mathrm{kg}$ & $\begin{array}{l}\text { Cisplatin-induced CIPN } \\
\text { in mice }\end{array}$ & $\begin{array}{l}\text { Preventing the reduction in NCV, number of migrating cells, and } \\
\text { length of outgrowing axons caused by cisplatin }\end{array}$ & Lee et al., 2012 \\
\hline & $50-150 \mathrm{mg} / \mathrm{kg}$ & $\begin{array}{l}\text { Vincristine-induced } \\
\text { CIPN in rats }\end{array}$ & $\begin{array}{l}\text { Increased the paw withdrawal threshold to mechanical stimuli, } \\
\text { reduced withdrawal frequency to cold stimuli }\end{array}$ & Park et al., 2012 \\
\hline Green tea & $300 \mathrm{mg} / \mathrm{kg}$ & $\begin{array}{l}\text { Oxaliplatin-induced } \\
\text { CIPN in rats }\end{array}$ & $\begin{array}{l}\text { Alleviate sensory symptoms such as allodynia, but did not prevent } \\
\text { morphometric or electrophysiological alterations induced by } \\
\text { oxaliplatin }\end{array}$ & Wang et al., 2008 \\
\hline Ocimum sanctum (L.) & $100-200 \mathrm{mg} / \mathrm{kg}$ & $\begin{array}{l}\text { Vincristine-induced } \\
\text { CIPN }\end{array}$ & $\begin{array}{l}\text { Attenuated vincristine-induced painful neuropathic state along with } \\
\text { decrease in oxidative stress and calcium levels }\end{array}$ & Kaur et al., 2010 \\
\hline Matricaria chamomilla & $25 \mathrm{mg} / \mathrm{kg}$ & Cisplatin-induced CIPN & Decrease of pain responses in the first and second phase & $\begin{array}{l}\text { Namvaran Abbas Abad } \\
\text { et al., } 2011\end{array}$ \\
\hline Butea monosperma & $400 \mathrm{mg} / \mathrm{kg}$ & $\begin{array}{l}\text { Vincristine-induced } \\
\text { CIPN }\end{array}$ & $\begin{array}{l}\text { Attenuated vincristine-induced painful behavioural, } \\
\text { histopathological changes and alterations of oxidative stress marker }\end{array}$ & Thiagarajan et al., 2013 \\
\hline Walnut & $6 \%$ & $\begin{array}{l}\text { Cisplatin-induced CIPN } \\
\text { in rats }\end{array}$ & $\begin{array}{l}\text { Improved memory and motor abilities in cisplatin treated rats, } \\
\text { reduced latency of response to nociception }\end{array}$ & Shabani et al., 2012 \\
\hline Xylopia aethiopica & $30-300 \mathrm{mg} / \mathrm{kg}$ & $\begin{array}{l}\text { Vincristine-induced } \\
\text { CIPN }\end{array}$ & $\begin{array}{l}\text { Exhibited anti-hyperalgesic, tactile, and cold anti-allodynic } \\
\text { properties }\end{array}$ & Ameyaw et al., 2014 \\
\hline Curcumin & $10 \mathrm{mg} / \mathrm{kg}$ & $\begin{array}{l}\text { Oxaliplatin and cisplatin } \\
\text { neurotoxicity in rats }\end{array}$ & $\begin{array}{l}\text { Reversed the alterations in the plasma neurotensin and sciatic } \\
\text { nerve platinum concentrations, and markedly improved sciatic } \\
\text { nerve histology in the platinum-treated rats }\end{array}$ & Al Moundhri et al., 2013 \\
\hline Auraptenol & $0.05-0.8 \mathrm{mg} / \mathrm{kg}$ & $\begin{array}{l}\text { Vincristine-induced } \\
\text { CIPN in mice }\end{array}$ & Dose-dependently reverted the mechanical hyperalgesia & Wang et al., 2013 \\
\hline Quercetin & $50 \mathrm{mg} / \mathrm{kg}$ & $\begin{array}{l}\text { Oxaliplatin-induced } \\
\text { CIPN in mice }\end{array}$ & $\begin{array}{l}\text { Prevented oxaliplatin induced painful peripheral neuropathy, } \\
\text { prevented lipid peroxidation and tyrosine nitrosylation }\end{array}$ & Azevedo et al., 2013 \\
\hline \multirow[t]{2}{*}{ Goshajinkigan } & $0.3-1 \mathrm{~g} / \mathrm{kg}$ & $\begin{array}{l}\text { Oxaliplatin-induced } \\
\text { CIPN in rat }\end{array}$ & $\begin{array}{l}\text { Prevent oxaliplatin-induced cold hyperalgesia but not mechanical } \\
\text { allodynia and axonal degeneration of the rat sciatic nerve }\end{array}$ & Andoh et al., 2014 \\
\hline & $1 \mathrm{~g} / \mathrm{kg}$ & $\begin{array}{l}\text { Paclitaxel-induced } \\
\text { CIPN in mice }\end{array}$ & $\begin{array}{l}\text { Prevent paclitaxel-induced allodynia without affecting the anticancer } \\
\text { action }\end{array}$ & Kono et al., 2011 \\
\hline Guilongtongluofang & $200 \mathrm{~mL} /$ day & $\begin{array}{l}\text { A randomized, } \\
\text { double-blind, } \\
\text { placebo-controlled trial }\end{array}$ & $\begin{array}{l}\text { Reduce the incidence of neurotoxicity without reducing the efficacy } \\
\text { of chemotherapy }\end{array}$ & Liu et al., 2013 \\
\hline
\end{tabular}

have reported that catechins possess potent antioxidant and anti-inflammatory activities, and have been shown to prevent cancer and improve chemotherapy-induced side effects (Zaveri, 2006). The beneficial effect of green tea in ameliorating experimental CIPN was assessed in oxaliplatin-treated rats (Lee et al., 2012). Coadministration of green tea at $300 \mathrm{mg} / \mathrm{kg}$ for 6 weeks effectively alleviated mechanical allodynia and thermal hyperalgesia induced by oxaliplatin. However, the exact mechanisms responsible for antiallodynic and antihyperalgesic activity of green tea are not clear.

\section{Goshajinkigan}

Goshajinkigan (GJG) is a widely used Kampo medicine containing 10 different herbs (Rehmannia viride radix, Achyranthis bidentatae radix, Corni fructus, Dioscorea opposita rhizoma, Plantaginis semen, Alismatis rhizoma, Moutan cortex, Cinnamomi cortex, Aconiti lateralis praeparata tuber, and Poria alba). Prescription of GJG to diabetic patients can improve neuropathy symptoms such as numbness, cold sensation, and limb pain (Uno et al., 2005). In recent years, the effect of GJG on CIPN has been extensively explored. In CIPN rats, GJG treatment was able to reduce cold hyperalgesia and mechanical allodynia, and no regeneration was found in histological examination (Ushio et al., 2012; Bahar et al., 2013; Andoh et al., 2014). More importantly, GJG showed little effect on the antitumour activity of anticancer drugs. The neuroprotection of GJG has also been supported by clinical studies. In a retrospective analysis included 45 patients with colorectal cancer, 22 received GJG during their FOLFOX regimen, while 23 did not get this additional therapy. After 10 courses of chemotherapy, the prevalence of grade 3 peripheral neuropathy in the GJG group was $0 \%$, while $12 \%$ in the control group. After 20 courses, the incidence in the GJG group increased to $33 \%$, significantly lower than that in patients without GJG administration (75\%; Kono et al., 2011; Nishioka et al., 2011). Results from large clinical trials enrolling patients with colorectal, breast, and gynecological cancers further support the protective effect of GJG (Yamamoto et al., 2009). Although GJG is effective for treating CIPN, its underlying molecular and cellular mechanisms remain poorly understood. Several laboratory studies indicated that GJG improved peripheral nociception and circulation through promoting NO production, increasing hippocampal c-Fos and nerve growth factor expression, and suppressing functional alteration of TRP channels such as TRPA1 and TRPM8 (Yamamoto et al., 2009; Mizuno et al., 2014). 


\section{Other Herbal Medicines}

In addtion to the phytochemicals and herbs mentioned above, several other compunds or herbal mixtures also presented positive effect on CIPN treatment. For example, auraptenol, a coumarin component isolated from Angelicae Dahuricae Radix, was reported to protect mice from vincristineinduced neuropathic pain (Wang et al., 2013). After auraptenol treatment $(0.8 \mathrm{mg} / \mathrm{kg})$, mechanical hyperalgesia was totally suppressed. African pepper may inhibit p38 and/or ERK1 and ERK2 pathways, and prevent pain stimuli propagation in the degenerated C-, $\mathrm{A} \delta$-, and $\mathrm{A} \beta$-fibers, thereby reversing mechanical hyperalgesia and cold allodynia (Ameyaw et al., 2014). In vincristine-induced neurotoxicity of rat model, Ocimum sanctum (L.) lowered the level of oxidative stress and calcium, thus helping to prevent CIPN symptoms (Kaur et al., 2010). Guilong tongluo formula (GLTLF) has also been shown to reduce CIPN symptoms. After four cycles of treatment, the percentage of neurotoxicity in GLTLF-treated group was 51.7\% compared with $70.0 \%$ for placebo-treated group (Liu et al., 2013). In addition, the onset of sensory neurotoxicity was much later in patients who received GLTLF.

\section{Acupuncture}

Cancer patients often seek CAM help for treatment-related side effects. Acupuncture, stimulating the special body points by the thin needles, is one of the most frequently used remedies, and effective for various adverse reactions resulting from chemotherapy or radiation therapy (Dean-Clower et al., 2010). Recently, acupuncture has been tested for CIPN in experimental models and clinical trials (Schroeder et al., 2012). The results demonstrated that intervention with acupuncture can increase limb blood flow, promote nerve repair, inhibit peripheral nerves degradation and induce a normalization of histological morphology (Litscher et al., 2002; Xu et al., 2010). The benifical role of acupuncture on CIPN may be mediated by the enhancement of spinal/central GABA-ergic, serotoninergic, and adrenergic neurotransmission, as well as the parallel decrease in sensory neurons hypersensitization (Park et al., 2010; Silva et al., 2011). With cDNA microarray analysis, it was found that the ation of mechanism of acupuncture involved signal translation, gene expression, and nociceptive pathways (Ko et al., 2002). Acupuncture seems promising because of its safety and low cost. According to American College of Chest Physicians evidence-based clinical practice guidelines for lung cancer, complementary acupuncture is recommended when pain is poorly controlled or neuropathy is clinically significant (Cassileth et al., 2007). However, for extensive application in CIPN, the efficacy of acupuncture still needs to be confirmed by more rigorous randomized controlled clinical studies.

\section{REFERENCES}

Akira, S., and Takeda, K. (2004). Toll-like receptor signalling. Nat. Rev. Immunol. 4, 499-511. doi: 10.1038/nri1391

Al Moundhri, M. S., Al-Salam, S., Al Mahrouqee, A., Beegam, S., and Ali, B. H. (2013). The effect of curcumin on oxaliplatin and cisplatin neurotoxicity in rats. J. Med. Toxicol. 9, 25-33. doi: 10.1007/s13181-012-0239-x

\section{CONCLUSION AND FUTURE PROSPECTS}

As a prominent dose-limiting side effect in chemotherapy, CIPN is attached great importance. Due to multiple mechanisms of neuronal demage, a combination of components focusing on multiple targets of CIPN might be promising. Recently, CAM therapies including herbal medicines and acupuncture have been intensively studied for CIPN prevention and show promising results. However, the scientific evidence supporting their efficacy is strikingly limited. Furthermore, the dosages of some herbal medicines used in rodent models seem quite high, and some herbs still cause hepatic or renal toxicity at high dosages. Therefore, it is necessary and important to confirm whether the dosages could be interpretated to clinical settings and determine the toxicity dosage of herbal preparation. Acupuncture in CIPN management has been pomising, yet, the studies quality conducted is low. The postition, depth, and angle of the needle insertion are not cosistent, which need to be improved in interpreting the findings. In summary, when considering CAMs use in the treatment of CIPN, the therapeutic potential of alternative therapies still needs to be rigorously investigated with large scale randomized controlled trials. Additionally, the interactions of CAMs with chemotherapy, potential toxicities associated herb medicines, as well as molecular mechanisms and bioactive compounds responsible for the neuroprotective effects should also be further investigated.

\section{AUTHOR CONTRIBUTIONS}

All authors fulfil the authorship requirements and have approved the final version of the manuscript. PC, XW, and $\mathrm{JH}$ developed the paper design and revised the manuscript. QW contributed to revise the manuscript. $\mathrm{XC}$ and HL wrote the first draft of the manuscript to which all authors made significant subsequent contributions.

\section{ACKNOWLEDGMENTS}

This study received support from National Natural Science Foundation of China (NO.81403092, NO.81473377, NO. 81274150, NO. 81573665), and was also funded by grants from Science Foundation for Distinguished Young Scholars of Jiangsu Province (No. BK20140049).

Alessandri-Haber, N., Dina, O. A., Joseph, E. K., Reichling, D. B., and Levine, J. D. (2008). Interaction of transient receptor potential vanilloid 4, integrin, and SRC tyrosine kinase in mechanical hyperalgesia. J. Neurosci. 28, 1046-1057. doi: 10.1523/JNEUROSCI.4497-07.2008

Ameyaw, E. O., Woode, E., Boakye-Gyasi, E., Abotsi, W. K., Kyekyeku, J. O., and Adosraku, R. K. (2014). Anti-allodynic and Anti-hyperalgesic effects of an ethanolic extract and xylopic acid from the fruits of Xylopia aethiopica 
in murine models of neuropathic pain. Pharmacognosy Res. 6, 172-179. doi: 10.4103/0974-8490.129041

Anand, U., Otto, W. R., and Anand, P. (2010). Sensitization of capsaicin and icilin responses in oxaliplatin treated adult rat DRG neurons. Mol. Pain 6:82. doi: 10.1186/1744-8069-6-82

Andoh, T., Kitamura, R., Fushimi, H., Komatsu, K., Shibahara, N., and Kuraishi, Y. (2014). Effects of goshajinkigan, hachimijiogan, and rokumigan on mechanical allodynia induced by Paclitaxel in mice. J. Tradit. Complement. Med. 4, 293-297. doi: 10.4103/2225-4110.128906

Argyriou, A. A., Cavaletti, G., Antonacopoulou, A., Genazzani, A. A., Briani, C., Bruna, J., et al. (2013). Voltage-gated sodium channel polymorphisms play a pivotal role in the development of oxaliplatin-induced peripheral neurotoxicity:results from a prospective multicenter study. Cancer 119, 35703577. doi: 10.1002/cncr.28234

Argyriou, A. A., Kyritsis, A. P., Makatsoris, T., and Kalofonos, H. P. (2014). Chemotherapy-induced peripheral neuropathy in adults: a comprehensive update of the literature. Cancer Manag. Res. 6, 135-147. doi: 10.2147/CMAR.S44261

Ataie, A., Sabetkasaei, M., Haghparast, A., Moghaddam, A. H., and Kazeminejad, B. (2010). Neuroprotective effects of the polyphenolic antioxidant agent, curcumin, against homocysteine-induced cognitive impairment and oxidative stress in the rat. Pharmacol. Biochem. Behav. 96, 378-385. doi: 10.1016/j.pbb.2010.06.009

Attia, H. N., Al-Rasheed, N. M., Al-Rasheed, N. M., Maklad, Y. A., Ahmed, A. A., and Kenawy, S. A. (2012). Protective effects of combined therapy of gliclazide with curcumin in experimental diabetic neuropathy in rats. Behav. Pharmacol. 23, 153-161. doi: 10.1097/FBP.0b013e3283512c00

Azevedo, M. I., Pereira, A. F., Nogueira, R. B., Rolim, F. E., Brito, G. A., Wong, D. V., et al. (2013). The antioxidant effects of the flavonoids rutin and quercetin inhibit oxaliplatin-induced chronic painful peripheral neuropathy. Mol. Pain 9:53. doi: 10.1186/1744-8069-9-53

Bahar, M. A., Andoh, T., Ogura, K., Hayakawa, Y., Saiki, I., and Kuraishi, Y. (2013). Herbal medicine goshajinkigan prevents paclitaxel-induced mechanical allodynia without impairing antitumor activity of paclitaxel. Evid Based Complement. Alternat. Med. 2013, 849754. doi: 10.1155/2013/8 49754

Bennett, G. J., Liu, G. K., Xiao, W. H., Jin, H. W., and Siau, C. (2011). Terminal arbor degeneration-a novel lesion produced by the antineoplastic agent paclitaxel. Eur. J. Neurosci. 33, 1667. doi: 10.1111/j.1460-9568.2011.0 7652.x

Boyette-Davis, J., Xin, W., Zhang, H., and Dougherty, P. M. (2011). Intraepidermal nerve fiber loss corresponds to the development of taxol-induced hyperalgesia and can be prevented by treatment with minocycline. Pain 152, 308-313. doi: 10.1016/j.pain.2010.10.030

Broyl, A., Corthals, S. L., Jongen, J. L., van der Holt, B., Kuiper, R., de Knegt, Y., et al. (2010). Mechanisms of peripheral neuropathy associated with bortezomib and vincristine in patients with newly diagnosed multiple myeloma: a prospective analysis of data from the HOVON-65/GMMG-HD4 trial. Lancet Oncol. 11, 1057-1065. doi: 10.1016/S1470-2045(10)70206-0

Carozzi, V. A., Canta, A., and Chiorazzi, A. (2015). Chemotherapy-induced peripheral neuropathy: what do we know about mechanisms. Neurosci. Lett. 596, 90-107. doi: 10.1016/j.neulet.2014.10.014

Cassileth, B. R., Deng, G. E., Gomez, J. E., Johnstone, P. A., Kumar, N., and Vickers, A. J. (2007). Complementary therapies and integrative oncology in lung cancer: ACCP evidence-based clinical practice guidelines (2nd edition). Chest 132, 340S-354S. doi: 10.1378/chest.07-1389

Cavaletti, G. (2011). Calcium and magnesium prophylaxis for oxaliplatin-related neurotoxicity: is it a trade-off between drug efficacy and toxicity? Oncologist 16, 1667-1668. doi: 10.1634/theoncologist.2011-0343

Cavaletti, G., Ceresa, C., Nicolini, G., and Marmiroli, P. (2014). Neuronal drug transporters in platinum drugs-induced peripheral neurotoxicity. Anticancer. Res. 34, 483-486.

Ceresa, C., and Cavaletti, G. (2011). Drug transporters in chemotherapy induced peripheral neurotoxicity: current knowledge and clinical implications. Curr. Med. Chem. 18, 329-341. doi: 10.2174/092986711794 839160

Ciarimboli, G., Deuster, D., Knief, A., Sperling, M., Holtkamp, M., Edemir, B., et al. (2010). Organic cation transporter 2 mediates cisplatin-induced oto- and nephrotoxicity and is a target for protective interventions. Am. J. Pathol. 176, 1169-1180. doi: 10.2353/ajpath.2010.090610

Dean-Clower, E., Doherty-Gilman, A. M., Keshaviah, A., Baker, F., Kaw, C., Lu, W., et al. (2010). Acupuncture as palliative therapy for physical symptoms and quality of life for advanced cancer patients. Integr. Cancer Ther. 9, 158-167. doi: $10.1177 / 1534735409360666$

Di Cesare, M. L., Zanardelli, M., Failli, P., and Ghelardini, C. (2012). Oxaliplatininduced neuropathy: oxidative stress as pathological mechanism. protective effect of silibinin. J. Pain 13, 276-284. doi: 10.1016/j.jpain.2011.11.009

Fidanboylu, M., Griffiths, L. A., and Flatters, S. J. L. (2011). Global inhibition of reactive oxygen species (ROS) inhibits paclitaxel-induced painful peripheral neuropathy. PLoS ONE 6:e25212. doi: 10.1371/journal.pone.0025212

Flatters, S. J., and Bennett, G. J. (2004). Ethosuximide reverses paclitaxel and vincristine induced painful peripheral neuropathy. Pain 109, 150-161. doi: 10.1016/j.pain.2004.01.029

Flatters, S. J. L., Xiao, W. H., and Bennett, G. J. (2006). Acetyl-L-carnitine prevents and reduces paclitaxel-induced painful peripheral neuropathy. Neurosci. Lett. $397,219-223$.

Florea, A. M., and Büsselberg, D. (2011). Cisplatin as an anti-tumor drug: cellular mechanisms of activity, drug resistance and induced side effects. Cancers 3, 1351-1371. doi: 10.3390/cancers3011351

Gamelin, L., Boisdron-Celle, M., Morel, A., Poirier, A. L., Berger, V., Gamelin, E., et al. (2008). Oxaliplatin-related neurotoxicity: interest of calcium-magnesium infusion and no impact on its efficacy. J. Clin. Oncol. 26, 1188-11899. doi: 10.1200/JCO.2007.15.3767

GaneshYerra, V., Negi, G., Sharma, S. S., and Kumar, A. (2013). Potential therapeutic effects of the simultaneous targeting of the Nrf2 and NF$\kappa \mathrm{B}$ pathways in diabetic neuropathy. Redox Biol. 1, 394-397. doi: 10.1016/j.redox.2013.07.005

Gauchan, P., Andoh, T., Ikeda, K., Fujita, M., Sasaki, A., Kato, A., et al. (2009a). Mechanical allodynia induced by paclitaxel, oxaliplatin and vincristine: different effectiveness of gabapentin and different expression of voltagedependent calcium channel alpha(2)delta-1 subunit. Biol. Pharm. Bull. 32, 732-734. doi: 10.1248/bpb.32.732

Gauchan, P., Andoh, T., Kato, A., and Kuraishi, Y. (2009b). Involvement of increased expression of transient receptor potential melastatin 8 in oxaliplatin-induced cold allodynia in mice. Neurosci. Lett. 458, 93-95. doi: 10.1016/j.neulet.2009.04.029

Gobran, N. S. (2013). Role of calcium and magnesium infusion in prevention of oxaliplatin neurotoxicity. A phase III trial. Chinese-German J. Clin. Oncol. 12, 232-236. doi: 10.1007/s10330-013-1161-7

Goswami, C. (2012). TRPV1-tubulin complex: involvement of membrane tubulin in the regulation of chemotherapy-induced peripheral neuropathy. J. Neurochem. 123, 1-13. doi: 10.1111/j.1471-4159.2012. 07892.X

Han, Y., and Smith, M. T. (2013). Pathobiology of cancer chemotherapyinduced peripheral neuropathy (CIPN). Front. Pharmacol. 4:156. doi: 10.3389/fphar.2013.00156

Hara, T., Chiba, T., Abe, K., Makabe, A., Ikeno, S., Kawakami, K., et al. (2013). Effect of paclitaxel on transient receptor potential vanilloid 1 in rat dorsal root ganglion. Pain 154, 882-889. doi: 10.1016/j.pain.2013. 02.023

Hershman, D. L., Lacchetti, C., Dworkin, R. H., Smith, E. M. L., Bleeker, J., and Cavaletti, G. (2014). Prevention and management of chemotherapy-induced peripheral neuropathy in survivors of adult cancers: american Society of Clinical Oncology Clinical Practice Guideline. J. Clin. Oncol. 32, 1941-1967. doi: 10.1200/JCO.2013.54.0914

Hutchinson, M. R., Zhang, Y., Brown, K., Coats, B. D., Shridhar, M., Sholar, P. W., et al. (2008). Non-stereoselective reversal of neuropathic pain by naloxone and naltrexone: involvement of toll-like receptor 4 (TLR4). Eur. J. Neurosci. 28, 20-29. doi: 10.1111/j.1460-9568.2008.06321.x

Jaggi, A. S., and Singh, N. (2012). Mechanisms in cancer-chemotherapeutic drugs-induced peripheral neuropathy. Toxicology 291, 1-9. doi: 10.1016/j.tox.2011.10.019

Kandhare, A. D., Raygude, K. S., Ghosh, P., Ghule, A. E., and Bodhankar, S. L. (2012). Therapeutic role of curcumin in prevention of biochemical and behavioral aberration induced by alcoholic neuropathy in laboratory animals. Neurosci. Lett. 511, 18-22. doi: 10.1016/j.neulet.2012.01.019 
Kaur, G., Jaggi, A. S., and Singh, N. (2010). Exploring the potential effect of Ocimum Sanctum in vincristine-induced neuropathic pain in rats. J. Brachial Plex. Peripher. Nerve Inj. 5:3. doi: 10.1186/1749-7221-5-3

Kim, H. K., Zhang, Y. P., Gwak, Y. S., and Abdi, S. (2011). Phenyl $\mathrm{N}$-tert-butylnitrone, a free radical scavenger, reduces mechanical allodyniain chemotherapy-induced neuropathic pain in rats. Anesthesiology 112, 432-439. doi: 10.1097/ALN.0b013e3181ca31bd

Ko, J., Na, D. S., Lee, Y. H., Shin, S. Y., Kim, J. H., Hwang, B. G., et al. (2002). cDNA microarray analysis of the differential gene expression in the neuropathic pain and electroacupuncture treatment models. J. Biochem. Mol. Biol. 35, 420-427. doi: 10.5483/BMBRep.2002.35.4.420

Kono, T., Mamiya, N., Chisato, N., Ebisawa, Y., Yamazaki, H., Watari, J., et al. (2011). Efficacy of goshajinkigan for peripheral neurotoxicity of oxaliplatin in patients with advanced or recurrent colorectal cancer. Evid Based Complement. Alternat. Med. 2011:418481. doi: 10.1093/ecam/nep200

Leal, A. D., Qin, R., Atherton, P. J., Haluska, P., Behrens, R. J., Tiber, C. H., et al. (2014). North Central Cancer Treatment Group/Alliance trial N08CA-the use of glutathione for prevention of paclitaxel/carboplatin-induced peripheral neuropathy: a phase 3 randomized, double-blind, placebo-controlled study. Cancer 120, 1890-1897. doi: 10.1002/cncr.28654

Ledeboer, A., Jekich, B. M., Sloane, E. M., Mahoney, J. H., Langer, S. J., Milligan, E. D., et al. (2007). Intrathecal interleukin-10 gene therapy attenuates paclitaxelinduced mechanical allodynia and proinflammatory cytokine expression in dorsal root ganglia in rats. Brain Behav. Immun. 21, 686-698. doi: 10.1016/j.bbi.2006.10.012

Lee, J. S., Kim, Y. T., Jeon, E. K., Won, H. S., Cho, Y. S., and Ko, Y. H. (2012). Effect of green tea extracts on oxaliplatin-induced peripheral neuropathy in rats. $B M C$ Complement. Altern. Med. 12:124. doi: 10.1186/1472-6882-12-124

Litscher, G., Wang, L., Huber, E., and Nilsson, G. (2002). Changed skin blood perfusion in the finger tip following acupuncture needle introduction as evaluated by laser Doppler perfusion imaging. Lasers Med. Sci. 17, 19-25. doi: $10.1007 /$ s10103-002-8262-9

Liu, Y., Zhu, G. Y., Han, L., Liu, J., Ma, T., and Yu, H. M. (2013). Clinical study on the prevention of oxaliplatin-induced neurotoxicity with guilongtongluofang: results of a randomized, double-blind, placebo-controlled trial. Evid Based Complement. Alternat. Med. 2013:541217. doi: 10.1155/2013/541217

Loprinzi, C., Qin, R., Dakhil, S. R., Fehrenbacher, L., Flynn, K. A., Atherton, P., et al. (2014). Phase III randomized, placebo (PL)-controlled, double-blind study of intravenous calcium/magnesium ( $\mathrm{CaMg}$ ) to prevent oxaliplatin-induced sensory neurotoxicity (sNT), N08CB: an alliance for clinical trials in oncology study. J. Clin. Oncol. 32:997. doi: 10.1200/JCO.2013.52.0536

Mangiacavalli, S., Corso, A., De Amici, M., Varettoni, M., Alfonsi, E., Lozza, A., et al. (2010). Emergent T-helper 2 profile with high interleukin-6 levels correlates with the appearance of bortezomib-induced neuropathic pain. $\mathrm{Br}$. J. Haematol. 149, 916-918. doi: 10.1111/j.1365-2141.2010.08138.x

Melli, G., Taiana, M., Camozzi, F., Triolo, D., Podini, P., Quattrini, A., et al. (2008). Alpha-lipoic acid prevents mitochondrial damage and neurotoxicity in experimental chemotherapy neuropathy. Exp. Neurol. 214, 276-284. doi: 10.1016/j.expneurol.2008.08.013

Mendonça, L. M., da Silva Machado, C., Teixeira, C. C., de Freitas, L. A., Bianchi Mde, L., and Antunes, L. M. (2013). Curcumin reduces cisplatin-induced neurotoxicity in NGF-differentiated PC12 cells. Neurotoxicology 34, 205-211. doi: 10.1016/j.neuro.2012.09.011

Miltenburg, N. C., and Boogerd, W. (2014). Chemotherapy-induced neuropathy: a comprehensive survey. Cancer Treat. Rev. 40, 872-882. doi: $10.1016 /$ j.ctrv.2014.04.004

Mizuno, K., Kono, T., Suzuki, Y., Miyagi, C., Omiya, Y., Miyano, K., et al. (2014). Goshajinkigan, a traditional Japanese medicine, prevents oxaliplatininduced acute peripheral neuropathy by suppressing functional alteration of TRP channels in rat. J. Pharmacol. Sci. 125, 91-98. doi: 10.1254/jphs. $13244 \mathrm{FP}$

Namvaran Abbas Abad, A., Kayate Nourib, M. H., Gharjaniec, A., and Tavakolid, F. (2011). Effect of matricaria chamomilla hydroalcoholic extract on cisplatininduced neuropathy in mice. Chin. J. Nat. Med. 9, 126-131.

Nativi, C., Gualdani, R., Dragoni, E., Di Cesare Mannelli, L., Sostegni, S., Norcini, M., et al. (2013). TRPA1 antagonist reverts oxaliplatin-induced neuropathic pain. Sci. Rep. 3:2005. doi: 10.1038/srep02005
Negi, G., Kumar, A., and Sharma, S. S. (2011). Nrf2 and NF-kB modulation by sulforaphane counteracts multiple manifestations of diabetic neuropathy in rats and high glucose-induced changes. Curr. Neurovasc. Res. 8, 294-304. doi: $10.2174 / 156720211798120972$

Nieto, F. R., Entrena, J. M., Cendán, C. M., Pozo, E. D., Vela, J. M., and Baeyens, J. M. (2008). Tetrodotoxin inhibits the development and expression of neuropathic pain induced by paclitaxel in mice. Pain 137, 520-531. doi: 10.1016/j.pain.2007.10.012

Nishioka, M., Shimada, M., Kurita, N., Iwata, T., Morimoto, S., Yoshikawa, K., et al. (2011). The Kampo medicine, Goshajinkigan, prevents neuropathy in patients treated by FOLFOX regimen. Int. J. Clin. Oncol. 16, 322-327. doi: 10.1007/s10147-010-0183-1

Oztürk, G., Anlar, O., Erdoğan, E., Kösem, M., Ozbek, H., and Türker, A. (2004). The effect of Ginkgo extract EGb761 in cisplatin-induced peripheral neuropathy in mice. Toxicol. Appl. Pharmacol. 196, 169-175. doi: 10.1016/j.taap.2003.12.006

Park, H. J., Lee, H. G., Kim, Y. S., Lee, J. Y., Jeon, J. P., Park, C., et al. (2012). Ginkgo biloba extract attenuates hyperalgesia in a rat model of vincristine-induced peripheral neuropathy. Anesth. Analg. 115, 1228-1233. doi: 10.1213/ANE.0b013e318262e170

Park, J. H., Han, J. B., Kim, S. K., Park, J. H., Go, D. H., Sun, B., et al. (2010). Spinal GABA receptors mediate the suppressive effect of electroacupuncture on cold allodynia in rats. Brain Res. 1322, 24-29. doi: 10.1016/j.brainres.2010. 02.001

Polomano, R., Clark, U., Mannes, A. J., and Bennett, G. J. (2001). A painful peripheral neuropathy in rat produced by the chemotherapeutic drug, paclitaxel. Pain 94, 293-304. doi: 10.1016/S0304-3959(01) 00363-3

Poratz, J. L., Knight, A. M., Ta, L. E., Staff, N. P., Gass, J. M., Genelin, K., et al. (2011). Cisplatin induced mitochondrial DNA damage in dorsal root ganglion neurons. Neurobiol. Dis. 41, 661-668. doi: 10.1016/j.nbd.2010.11.017

Quartu, M., Carozzi, V. A., Dorsey, S. G., Serra, M. P., Poddighe, L., Picci, C., et al. (2014). Bortezomib treatment produces nocifensive behavior and changes in the expression of TRPV1, CGRP, and substance P in the rat DRG, spinal cord, and sciatic nerve. Biomed. Res. Int. 2014:180428. doi: 10.1155/2014/1 80428

Raygude, K. S., Kandhare, A. D., Ghosh, P., Ghule, A. E., and Bodhankar, S. L. (2012). Evaluation of ameliorative effect of quercetin in experimental model of alcoholic neuropathy in rats. Inflammopharmacology 20, 331-341. doi: $10.1007 /$ s10787-012-0122-z

Sałat, K., Moniczewski, A., and Librowski, T. (2013). Transient receptor potential channels - emerging novel drug targets for the treatment of pain. Curr. Med. Chem. 20, 1409-1436. doi: 10.2174/09298673113209990107

Sandireddy, R., Yerra, V. G., Areti, A., Komirishetty, P., and Kumar, A. (2014). Neuroinflammation and oxidative stress in diabetic neuropathy: futuristic strategies based on these targets. Int. J. Endocrinol. 2014:674987. doi: $10.1155 / 2014 / 674987$

Schafers, M., and Sorkin, L. (2008). Effect of cytokines on neuronal excitability. Neurosci. Lett. 437, 188-193. doi: 10.1016/j.neulet.2008.03.052

Schroeder, S., Meyer-Hamme, G., and Epplée, S. (2012). Acupuncture for chemotherapy-induced peripheral neuropathy (CIPN): a pilot study using neurography. Acupunct. Med. 30, 4-7. doi: 10.1136/acupmed-2011-0 10034

Shabani, M., Nazeri, M., Parsania, S., Razavinasab, M., Zangiabadi, N., Esmaeilpour, K., et al. (2012). Walnut consumption protects rats against cisplatin-induced neurotoxicity. Neurotoxicology 33, 1314-1321. doi: 10.1016/j.neuro.2012.08.004

Silva, J. R. T., Silva, M. L., and Prado, W. A. (2011). Analgesia induced by 2- or $100-\mathrm{Hz}$ electroacupuncture in the rat tail-flick test depends on the activation of different descending pain inhibitory mechanisms. J. Pain 12, 51-60. doi: 10.1016/j.jpain.2010.04.008

Sittl, R., Lampert, A., Huth, T., Schuy, E. T., Link, A. S., Fleckenstein, J., et al. (2012). Anticancer drug oxaliplatin induces acute cooling-aggravated neuropathy via sodium channel subtype $\mathrm{Na}(\mathrm{V}) 1.6$-resurgent and persistent current. Proc. Natl. Acad. Sci. U.S.A. 109, 6704-9.

Sprowl, J. A., Ciarimboli, G., Lancaster, C. S., Giovinazzo, H., Gibson, A. A., Janke, L. J., et al. (2013). Oxaliplatin-induced neurotoxicity is dependent on 
the organic cation transporter OCT2. Proc. Natl. Acad. Sci. U.S.A. 110, 1119911204.

Ta, L. E., Bieber, A. J., Carlton, S. M., Loprinzi, C. L., Low, P. A., and Windebank, A. J. (2010). Transient receptor potential vanilloid 1 is essential for cisplatininduced heat hyperalgesia in mice. Mol. Pain 6:15. doi: 10.1186/1744-8069-6-15

Ta, L. E., Schmelzer, J. D., Bieber, A. J., Loprinzi, C. L., Sieck, G. C., Brederson, J. D., et al. (2013). A novel and selective poly (ADP-ribose) polymerase inhibitor ameliorates chemotherapy-induced painful neuropathy. PLOS ONE 8:e54161. doi: 10.1371/journal.pone.0054161

Thiagarajan, V. R., Shanmugam, P., Krishnan, U. M., Muthuraman, A., and Singh, N. (2013). Antinociceptive effect of Butea monosperma on vincristineinduced neuropathic pain model in rats. Toxicol. Ind. Health 29, 3-13. doi: $10.1177 / 0748233711432573$

Uno, T., Ohsawa, I., Tokudome, M., and Sato, Y. (2005). Effects of goshajinkigan on insulin resistance in patients with type 2 diabetes. Diabetes. Res. Clin. Pract. 69, 129-135. doi: 10.1016/j.diabres.2004.11.017

Ushio, S., Egashira, N., Sada, H., Kawashiri, T., Shirahama, M., Masuguchi, K., et al. (2012). Goshajinkigan reduces oxaliplatin-induced peripheral neuropathy without affecting anti-tumour efficacy in rodents. Eur. J. Cancer 48, 1407-1413. doi: 10.1016/j.ejca.2011.08.009

Wagner, K., Inceoglu, B., Gill, S. S., and Hammock, B. D. (2011). Epoxygenated fatty acids and soluble epoxide hydrolase inhibition: novel mediators of pain reduction. J. Agric. Food Chem. 59, 2816-2824. doi: 10.1021/jf102559q

Wang, H. T., Liu, Z. G., Yang, W., Liao, A. J., Zhang, R., Wu, B., et al. (2011). Study on mechanism of bortezomib inducing peripheral neuropathy and the reversing effect of reduced glutathione. Zhong Xue Ye Xue Za Zhi 32, 107-111.

Wang, J., Zhou, H., Jiang, Z., Wong, Y., and Liu, L. (2008). In vivo antiinflammatory and analgesic activities of a purified saponin fraction derived from the root of ilex pubescens. Biol. Pharm. Bull. 31, 643-650. doi: 10.1248/bpb.31.643

Wang, Y., Cao, S. E., Tian, J., Liu, G., Zhang, X., and Li, P. (2013). Auraptenol attenuates vincristine-induced mechanical hyperalgesia through serotonin 5HT1A receptors. Sci. Rep. 3:3377. doi: 10.1038/srep03377

Waseem, M., and Parvez, S. (2015). Neuroprotective activities of curcumin and quercetin with potential relevance to mitochondrial dysfunction induced by oxaliplatin. Protoplasma doi: 10.1007/s00709-015-0821-6 [Epub ahead of print].

Webster, R. G., Brain, K. L., Wilson, R. H., Grem, J. L., and Vincent, A. (2005). Oxaliplatin induces hyperexcitability at motor and autonomic neuromuscular junctions through effects on voltage-gated sodium channels. $\mathrm{Br}$. J. Pharmacol. 146, 1027-1039. doi: 10.1038/sj.bjp.0706407

Wolf, G., Gabay, E., Tal, M., Yirmiya, R., and Shavit, Y. (2006). Genetic impairment of interleukin-1 signaling attenuates neuropathic pain, autotomy, and spontaneous ectopic neuronal activity, following nerve injury in mice. Pain 120, 315-324. doi: 10.1016/j.pain.2005.11.011

Wolf, S., Barton, D., Kottschade, L., Grothey, A., and Loprinzi, C. (2008). Chemotherapy-induced peripheral neuropathy: prevention and treatment strategies. Eur. J. Cancer 44, 1507-1515. doi: 10.1016/j.ejca.2008. 04.018

Xiao, W. H., and Bennett, G. J. (2012). Effects of mitochondrial poisons on the neuropathic pain produced by the chemotherapeutic agents, paclitaxel and oxaliplatin. Pain 153, 704-709. doi: 10.1016/j.pain.2011.12.011

Xu, W. R., Hua, B. J., Hou, W., and Bao, Y. J. (2010). Clinical randomized controlled study on acupuncture for treatment of peripheral neuropathy induced by chemotherapeutic drugs. Zhongguo Jiu 30, 457-460.

Yamamoto, T., Murai, T., Ueda, M., Katsuura, M., Oishi, M., Miwa, Y., et al. (2009). Clinical features of paclitaxel-induced peripheral neuropathy and role of Gosya-jinki-gan. Gan To Kagaku Ryoho 36, 89-92.

Zaveri, N. T. (2006). Green tea and its polyphenolic catechins: medicinal uses in cancer and noncancer applications. Life Sci. 78, 2073-2080. doi: 10.1016/j.lfs.2005.12.006

Zhang, Y. Y., Li, G., Che, H., Sun, H. Y., Li, X., Au, W. K., et al. (2014). Characterization of functional ion channels in human cardiac c-kit + progenitor cells. Basic Res. Cardiol. 109:407. doi: 10.1007/s00395-014-0407-z

Zheng, H., Xiao, W. H., and Bennett, G. J. (2012). Mitotoxicity and bortezomibinduced chronic painful peripheral neuropathy. Exp. Neurol. 238, 225-234. doi: 10.1016/j.expneurol.2012.08.023

Conflict of Interest Statement: The authors declare that the research was conducted in the absence of any commercial or financial relationships that could be construed as a potential conflict of interest.

Copyright (C) 2015 Cheng, Liu, Wang, Huo, Wang and Cao. This is an open-access article distributed under the terms of the Creative Commons Attribution License (CC BY). The use, distribution or reproduction in other forums is permitted, provided the original author(s) or licensor are credited and that the original publication in this journal is cited, in accordance with accepted academic practice. No use, distribution or reproduction is permitted which does not comply with these terms. 